\title{
ANALYSIS OF FORMED CHIPS IN THE CASE OF TURNING DIFFERENT POLYMER MATERIALS
}

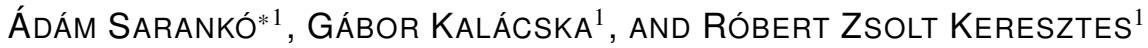 \\ ${ }^{1}$ Institute of Technology, Hungarian University of Agriculture and Life Sciences, Páter Károly u. 1, Gödöllő, \\ 2100, HUNGARY
}

In this paper, turning input parameters were defined for 12 different polymer materials that can be used in technical practices. Our goal was to determine turning input parameters where chip formation is favourable or continuous chips do not cause any problems. Our tests included the examination of detached chips and the values of the average surface roughness of the machined surfaces.

Keywords: chip formation, polymer materials, turning

\section{Introduction}

Nowadays, in addition to the 3D printing of polymers, the machining of polymer and polymer composite materials still plays an important role. Turning is one of the most productive machining technologies used to make cylindrical products. Polymers that exhibit good levels of machinability favour the development of chip formation. However, technical practices often use polymer materials that exhibit favourable properties (hardness, toughness, flexibility) but are difficult to machine. The most common problem is continuously flowing chips. In this case, rather than the chip being moved away from the material, it is pushed in front of the tool. As a result, the heat cannot dissipate from the chips and the detached chips are in constant contact with the tool, which generates additional heat. Since polymers tend to withstand high temperatures less than metals, their machined surfaces melt and their surface roughness becomes unacceptable.

Researchers have already studied the shape of detached chips. The literature is mainly concerned with the study of types of chips generated during the machining of metallic materials such as $\mathrm{C} 45$ [1,2], $\mathrm{Al} / \mathrm{SiCp}[3]$ and AISI D2 tool steel [4]. Kharlevich and Venuvinod analysed the formation of $3 \mathrm{D}$ chips in general as a result of metal cutting $[5,6]$, while others have researched methods of chip breaking for machining tools [7,8].

Although chip detachment and formation are very important aspects in machining, in the case of polymers, this area has not yet been investigated.

*Correspondence: saranko.adam@uni-mate.hu

\section{Experimental methods}

12 different polymer materials were tested, namely PA6 G-H, PA66 GF30, PET TF, PET, POM-C, POM-GF25, POM-H, PP,

PTFE, PVC, textile bakelite and UHMWPE. According to a manufacturer of polymer materials, the aforementioned materials are the most commonly used, excluding the so-called high-performance ones.

In this research, turning tests were performed to determine input parameters that can be used in practice to avoid such problems, e.g. melted surfaces, caused by continuously flowing chips. The turning tests were run on an E 400 conventional lathe machine and an NCT EUROturn-12B CNC lathe machine. Both devices are located in the workshop of the Institute of Technology. In all the experiments, a SCLCR 20.20 K09 tool shank and a CCGT 09T304-AS IC20 polished turning insert were used. After each test, a close-up photo of the surface was taken and the average surface roughness measured. For surface measurements, a Mitutoyo Surftest SJ-201P surface roughness tester was used. Furthermore, the formed chips were collected before being analysed.

The input parameters of all the tests are shown in Table 1 . In the case of roughing, the depth of cut was $3 \mathrm{~mm}$, while a depth of cut of $0.25 \mathrm{~mm}$ was used for finishing.

The air-cooled solution was mainly suitable for blowing off the detached chips. At first, all the experiments were tried without implementing any cooling methods. However, in the case of certain materials, flowing chips were formed in all cases, so chip blowing was used for these materials. 
Table 1: Input parameters of all tests

Input parameters for roughing on a CNC lathe machine (NCT EUROturn-12B)

\begin{tabular}{ccccccc} 
& PA6 G-H & PA66 GF30 & PET TF & PET & POM C & POM GF25 \\
\hline vc (m/min) & 250 & 250 & 250 & 250 & 250 & 250 \\
f (mm/rot.) & 0.2 & 0.2 & 0.15 & 0.15 & 0.2 & 0.2 \\
Cooling & - & - & - & - & - & - \\
& POM H & PP & PTFE & PVC & Textile bakelite & UHMW-PE \\
\hline vc (m/min) & 250 & 250 & 250 & 250 & 250 & 250 \\
f (mm/rot.) & 0.2 & 0.2 & 0.2 & 0.1 & 0.2 & 0.15 \\
Cooling & - & - & - & - & - & -
\end{tabular}

Input parameters for finishing on a CNC lathe machine (NCT EUROturn-12B)

\begin{tabular}{ccccccc} 
& PA-6 G-H & PA-66 GF-30 & PET TF & PET & POM C & POM GF-25 \\
\hline vc (m/min) & 300 & 300 & 300 & 300 & 300 & 300 \\
$\mathrm{f}(\mathrm{mm} /$ rot. $)$ & 0.1 & 0.1 & 0.1 & 0.1 & 0.1 & 0.1 \\
Cooling & air & air & air & air & air & air \\
& POM H & PP & PTFE & PVC & Textile bakelite & UHMW-PE \\
\hline vc (m/min) & 300 & 300 & 300 & 300 & 300 & 300 \\
$\mathrm{f} \mathrm{(mm/rot.)}$ & 0.1 & 0.1 & 0.1 & 0.1 & 0.08 & 0.1 \\
Cooling & air & air & air & air & - & air
\end{tabular}

Input parameters for roughing on a conventional lathe machine ( $E$ 400)

\begin{tabular}{ccccccc} 
& PA-6 G-H & PA-66 GF-30 & PET TF & PET & POM C & POM GF-25 \\
\hline vc (m/min) & 61 & 52 & 59 & 75 & 58 & 52 \\
$\mathrm{f}(\mathrm{mm} /$ rot. $)$ & 0.75 & 0.75 & 0.4 & 0.4 & 0.6 & 0.6 \\
Cooling & - & - & - & - & - & -
\end{tabular}

\begin{tabular}{ccccccc} 
& POM H & PP & PTFE & PVC & Textile bakelite & UHMW-PE \\
\hline $\mathrm{vc}(\mathrm{m} / \mathrm{min})$ & 66 & 76 & 58 & 58 & 59 & 58 \\
$\mathrm{f}(\mathrm{mm} / \mathrm{rot})$. & 0.6 & 0.75 & 0.6 & 0.2 & 0.75 & 0.4
\end{tabular}

Cooling

Input parameters for finishing on a conventional lathe machine ( $\mathrm{E} 400)$

\begin{tabular}{ccccccc} 
& PA-6 G-H & PA-66 GF-30 & PET TF & PET & POM C & POM GF-25 \\
\hline vc (m/min) & 65 & 62 & 63 & 79 & 62 & 62 \\
$\mathrm{f} \mathrm{(mm/rot.)}$ & 0.1 & 0.1 & 0.1 & 0.1 & 0.1 & 0.1 \\
Cooling & - & air & air & air & - & air \\
& POM H & PP & PTFE & PVC & Textile bakelite & UHMW-PE \\
\hline vc (m/min) & 71 & 80 & 57 & 63 & 63 & 62 \\
$\mathrm{f} \mathrm{(mm/rot.)}$ & 0.1 & 0.1 & 0.1 & 0.1 & 0.1 & 0.1 \\
Cooling & - & air & air & air & - & air
\end{tabular}

\section{Results}

The input parameters shown in Table 1 can also be considered as results. These parameters were determined experimentally.

In other aspects, however, the main results are the average surface roughness of the machined surfaces and the properties of the detached chips.

Table 2 shows the results of the average surface roughness measurements.

Although other setups can be used, by applying the parameters described above, safe and productive machining can be achieved by avoiding problems caused by con- tinuously flowing chips.

The detached chips were examined subjectively rather than by making specific measurements. However, the results obtained in this way can be used in practice and provide a suitable point of reference.

Photos of the detached chips in all cases are presented in Fig. 1, while the properties of these chips are shown in Table 3.

\section{Conclusions}

In general, the turning of tough polymeric materials results in the formation of continuous chips. Due to the big 
Table 2: Average surface roughness values

\begin{tabular}{l|cc|cc}
\hline Material & \multicolumn{4}{|c}{ Average surface roughness $(\mu \mathrm{m})$} \\
\hline & NCT EUROturn-12B & \multicolumn{2}{c}{ E 400 } \\
\hline PA6 G-H & 4.06 & 1.18 & 12.95 & 1.58 \\
PA66 GF30 & 3.12 & 1.27 & 12.32 & 1.55 \\
PET TF & 1.73 & 0.95 & 5.24 & 1.47 \\
PET & 1.75 & 0.9 & 5.18 & 1.13 \\
POM-C & 3.48 & 0.66 & 8.62 & 1.14 \\
POM-GF25 & 3.75 & 1.2 & 8.56 & 1.43 \\
POM-H & 3.44 & 0.68 & 8.72 & 1.14 \\
PP & 3.38 & 0.89 & 12.72 & 1.45 \\
PTFE & 5.01 & 1.77 & 18.44 & 1.93 \\
PVC & 1.01 & 0.78 & 2.35 & 0.87 \\
Textile bakelite & 6.81 & 3.15 & 10.30 & 1.59 \\
UHMWPE & 2.53 & 1.81 & 11.27 & 1.67 \\
\hline
\end{tabular}

Table 3: Properties of the detached chips

\begin{tabular}{l|cc|cc}
\hline & \multicolumn{4}{|c}{ Properties of the detached chips } \\
\hline & NCT EUROturn-12B & \multicolumn{2}{c}{ E 400 } \\
\hline PA6 G-H & Roughing & Finishing & Roughing & Finishing \\
PA66 GF30 & $5,6,7,8$ & $5,6,9$ & $5,6,8$ & $3,4,7$ \\
PET TF & 3,4 & 4,5 & 3,4 & 3,4 \\
PET & 4,5 & 4,5 & 3,10 & 4,5 \\
POM-C & 4,5 & 4,5 & 5,10 & 4,5 \\
POM-GF25 & 1,2 & 3,4 & 1,2 & 3,4 \\
POM-H & 1,2 & 1,2 & 1,2 & 3,4 \\
PP & 1,2 & 3,4 & 1,2 & 3,4 \\
PTFE & $4,5,6$ & 4,5 & 3,8 & 4,5 \\
PVC & 3,4 & 3,4 & 3,4 & 3,4 \\
Textile bakelite & 4,5 & 4,5 & 4,5 & 3,4 \\
UHMWPE & $3,6,7,10$ & $3,6,9$ & $3,6,7,8$ & $3,6,7$ \\
\hline 1: elemental, 2: rigid, 3: curved, continuously flowing, 4: easy to tear, 5: straight, \\
continuously flowing, 6: tough, 7: stretches, 8: does not tear, 9: tears after being \\
stretched, 10: hard to tear, 11: dust-like
\end{tabular}

cross-section of chips during the roughing operation, the mass of individual detached chips influences in which direction they start to flow. This is less of a problem because the ventilation effect of the chuck does not adversely affect the cooling of the chips.

In the case of the finishing operation, the cooling of the chips is critical. It is recommended to use air cooling, although not specifically for the purpose of cooling, in order to blow chips away from the workpiece and tool. Even though the quality of the machined surfaces can be improved by tools with bigger radius, chips can still cause problems. During the experiments, chip blowing was worthwhile in all cases, especially during smoothing operations.

Future research can be conducted by precisely defining the air-cooling method, applying other tools and investigating high-performance polymeric materials. In the case of chip blowing, the distance between the workpiece and the chuck, the weight of the detached chips as well as the ventilation effect of the chuck must be taken into account. The direction and velocity of the air is also significant. It was found that a strong airflow is not always the 


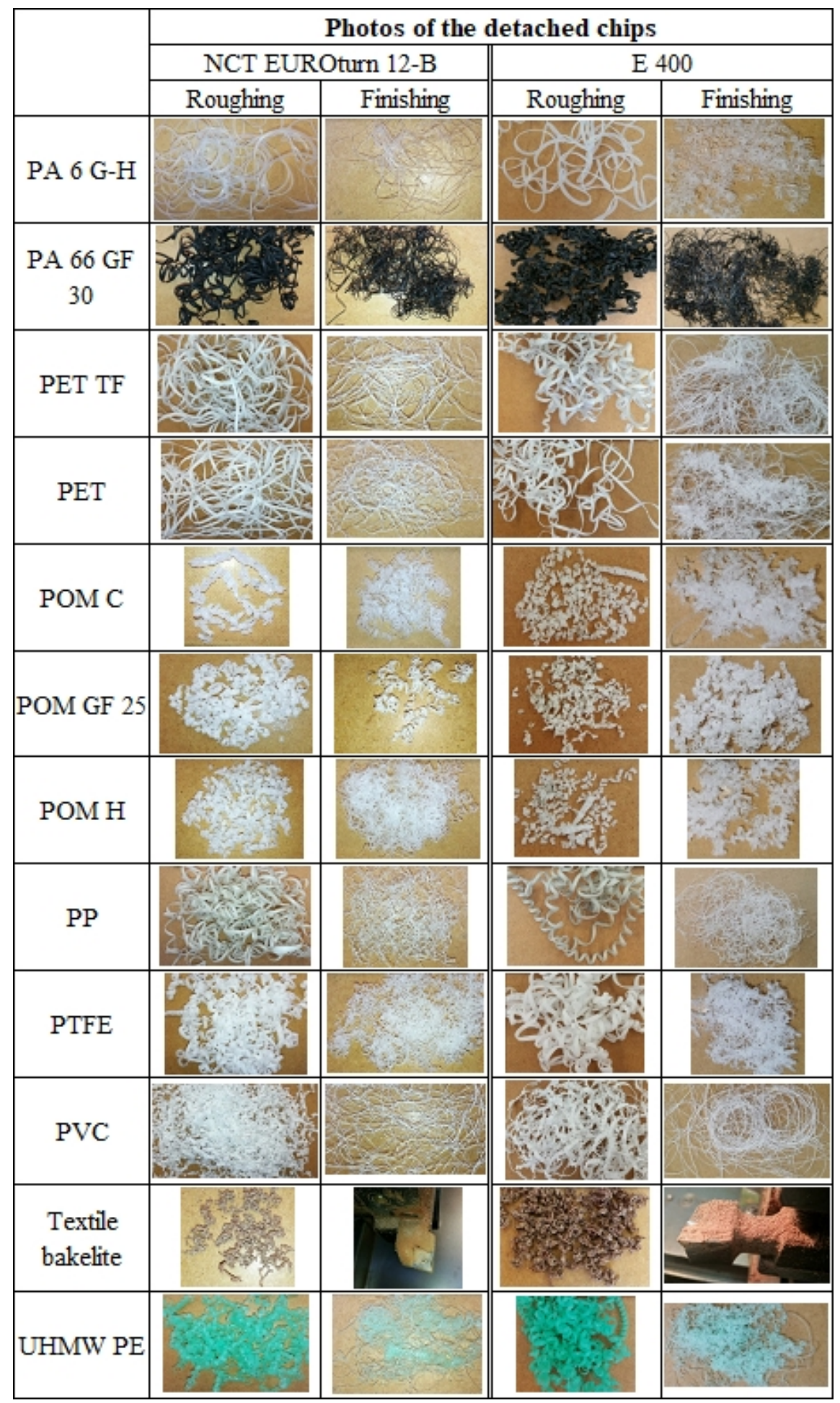

Figure 1: Photos of the detached chips

most desirable. The distance between the nozzle and the tool is limited by the geometries of the machine as well as the workpiece. By precisely defining these parameters, more practical information can be provided.

\section{Acknowledgement}

The authors would like to thank Quattroplast Kft. for providing the engineering polymeric materials.

\section{Nomenclature}

$v_{\mathrm{c}}$
$f$
$\mathrm{Ra}$
PA6 G-H
PA66 GF30
PET TF

cutting speed $(\mathrm{m} / \mathrm{min})$ feed rate ( $\mathrm{mm} /$ rotation) average surface roughness $(\mu \mathrm{m})$ cast polyamide 6 , Hungarian version polyamide 66 with $30 \mathrm{~m} / \mathrm{m} \%$ glass fiber polyethylene terephthalate with the addition of PTFE 


$\begin{array}{ll}\text { PTFE } & \text { polytetrafluoroethylene } \\ \text { PET } & \begin{array}{l}\text { polyethylene terephthalate } \\ \text { polyoxymethylene with } 25 \mathrm{~m} / \mathrm{m} \% \text { glass } \\ \text { POM-GF25 }\end{array} \\ \text { fiber } \\ \text { POM-C } & \text { polyoxymethylene copolymer } \\ \text { POM-H } & \text { polyoxymethylene homopolymer } \\ \text { PP } & \text { polypropylene } \\ \text { PVC } & \text { polyvinyl chloride } \\ \text { UHMWPE } & \text { ultra-high molecular weight polyethy- } \\ & \text { lene }\end{array}$

\section{REFERENCES}

[1] Segreto, T.; Simeone, A.; Teti, R.: Chip form Classification in Carbon Steel Turning through Cutting Force Measurement and Principal Component Analysis Procedia CIRP, 2012, 2, 49-54 DOI: 10.1016/j.procir.2012.05.038

[2] Segreto, T.; Simeone, A.; Teti, R.: Principal component analysis for feature extraction and NN pattern recognition in sensor monitoring of chip form during turning. CIRP J. Manuf. Sci. Technol. 2014, 7(3), 202-209 DOI: 10.1016/j.cirpj.2014.04.005

[3] Sun, W.; Duan, C.; Yin, W.: Chip formation mechanism in machining of $\mathrm{Al} / \mathrm{SiCp}$ composites based on analysis of particle damage. J. Manuf. Proc.. 2021, 64, 861-877 DOI: 10.1016/j.jmapro.2021.02.032

[4] Mohan, R.; Harshavardhana, N.; Chaudhari, M.; Jeyanthi, S.; Abimannan, G.: Analysis on surface finish and chip morphology during dry turning process. Mat. Today: Proc. 2021, 46(2), 999-1002 DOI: 10.1016/j.matpr.2021.01.137

[5] Kharkevich, A.; Venuvinod, P. K.: Basic geometric analysis of 3-D chip forms in metal cutting.: Part 2: implications. Int. J. Mach. Tools Manuf. 1999, 39(6), 965-983 DOI: 10.1016/S0890-6955(98)00066-2

[6] Kharkevich, A.; Venuvinod, P. K.: Extension of basic geometric analysis of 3-D chip forms in metal cutting to chips with obstacle-induced deformation. Int. J. Mach. Tools Manuf. 2002, 42(2), 201-213 DOI: 10.1016/S0890-6955(01)00115-8

[7] Wu, M.; Yu, A.; Chen, Q.; Wang, Y.; Yuan, J.; Sun, L.; Chi, J.: Design of adjustable chip breaker for PCD turning tools. Int. J. Mech. Sci.. 2020, (172), 105411 DOI: 10.1016/j.ijmecsci.2019.105411

[8] Yilmaz, B.; Karabulut, S.; Güllü, A.: A review of the chip breaking methods for continuous chips in turning. J. Manuf. Proc. 2020, 49, 50-69 DOI: 10.1016/j.jmapro.2019.10.026 